\title{
A cystic fibrosis patient homozygous for the nonsense mutation R553X
}

\author{
J Bal, M Stuhrmann, M Schloesser, J Schmidtke, J Reiss
}

\begin{abstract}
A cystic fibrosis patient homozygous for the nonsense mutation $\mathbf{R 5 5 3 X}$ was identified by mutation screening and the genotype confirmed by DNA sequencing. This patient, the only one described to date who is homozygous for this stop codon in exon 11 of the CFTR gene, is moderately severely affected. Clinical and molecular findings are presented.
\end{abstract}

Cystic fibrosis (CF) is the most frequent serious autosomal recessive disease in Caucasians, affecting approximately 1 in 2000 newborns. The gene is located on chromosome $7 \mathrm{q} 31$ and has been cloned and sequenced. ${ }^{12}$ The gene product is known as the 'cystic fibrosis transmembrane conductance regulator (CFTR)' and a structural model for this protein has been proposed. A large number of mutations in the CFTR gene associated with the CF phenotype have already been identified. ${ }^{34}$ It is, however, unclear if the highly variable clinical manifestation of CF is related to allelic heterogeneity or to other factors, either genetic or environmental. The most frequent mutation ( $\Delta \mathrm{F} 508)$ is located in exon 10 of the CFTR gene and is found on approximately $70 \%$ of $\mathrm{CF}$ chromosomes. ${ }^{5}$ In general, $\Delta \mathrm{F} 508$ is associated with severe CF.

Exons 9 to 12 are believed to encode the first of the two putative nucleotide binding folds. Cutting $e t a l^{\beta}$ reported a cluster of mutations in exon 11, two of which, G551D and R553X, are frequently found in most populations. The R553X mutation substitutes an arginine codon for a stop codon, which would be expected to result in a severely truncated protein. So far, reports of three patients with homozygosity or

Institute of Human Genetics, Universität Göttingen, Gosslerstrasse 12d, D-3400 Göttingen, Germany. J Bal, M Schloesser, J Reiss

\begin{abstract}
Department of Human Genetics, Medizinische Hochschule Hannover, Konstanty-GutschowStrasse 8, D-3000 Hannover 61, Germany. M Stuhrmann, J Schmidtke

Correspondence to Dr Reiss.
\end{abstract}

Received for publication 22 January 1991.

Revised version accepted for publication 8 April 1991. compound heterozygosity for stop mutations have been published. Cuppens et $a^{6}$ reported on a mildly affected patient who was homozygous for G542X and Cutting et $a l^{7}$ described two mildly affected patients with the genotypes W1316X/H553X and S1255X/G542X, respectively. We report here on a moderately severely affected patient who is homozygous for the nonsense mutation R553X.

\section{Methods}

One hundred and thirty-nine German cystic fibrosis patients with at least one non- $\Delta$ F508 allele were screened for mutations in exon 11 of the CFTR gene with restriction enzymes $\mathrm{HincII}$ and $\mathrm{MboI}$. $^{3}$ Seventeen of the total of 177 non- $\Delta F 508$ chromosomes exhibited the loss of a HincII site without the creation of a new $M b o I$ site. One patient was found to be homozygous for this type of deviation.

PCR amplified DNA of this patient encompassing the entire exon 11 was then directly sequenced on an automated fluorescence sequencer (Applied Biosystems, Foster City, model 373A) using protocols and labelled primers supplied by the vendor.

\section{Case report}

The proband was the first child born to healthy parents of German origin who are second degree relatives. His birth weight was $2950 \mathrm{~g}$ and length $52 \mathrm{~cm}$. Failure to thrive was noted at the age of 16 months. He started to produce copious fatty stools and developed rectal prolapse.

Sweat tests were initially in the normal range, but soon became borderline and were clearly positive with $160 \mathrm{mEq} / 1$ sodium chloride at the age of 2 years 4 months. The patient suffered from a recurrent cough and developed pronounced pulmonary manifestations of CF with chronic obstructive bronchitis and peribronchitis. Staphylococcus aureus and Pseudomonas aeruginosa were found in his sputum from this age onwards. Lung function was only moderately affected when tested repeatedly between the ages of 11 and $13 \frac{1}{2}$ years. Oral glucose tolerance was impaired at 11 years 9 months suggesting latent diabetes mellitus; stool chymotrypsin was then $11 \cdot 1 \mathrm{U} / \mathrm{g}$. 
Pancreatic enzyme substitution therapy was started at 2 years 4 months of age. Whereas height was between the 25 th and the 50 th centile throughout the time period assessed ( 2 years 4 months to $13 \frac{1}{2}$ years), his weight ranged only between well below the 3rd and the 10th centile. In view of this clinical picture, we tentatively classified this phenotype as moderately severe.

The sequence analysis of exon 11 of the patient is shown in the figure. Apart from the homozygous C1789GA to TGA alteration, no other deviation from the published wild type sequence was observed. Homozygosity for all RFLPs determined (table) and the consanguinity of the parents argue in favour of the two alleles being identical by descent.

\section{Discussion}

It is perhaps surprising that a nonsense mutation in the first half of the protein should have less dramatic
RFLP alleles determined for the $R 553 X / R 553 X$ patient. A summary of corresponding methods has been published. ${ }^{8}$

\begin{tabular}{lcc}
\hline Probe & Enzyme & Genotype \\
\hline metH & MspI & $1-1$ \\
metH & $T a q I$ & $1-1$ \\
XV2c & TaqI & $1-1$ \\
KM19 & PstI & $1-1$ \\
KM19 & Scrf & $2-2$ \\
Mp6d9 & MspI & $2-2$ \\
J44 & XbaI & $1-1$ \\
J3.11 & MspI & $2-2$ \\
J3.11 & PstI & $2-2$ \\
\hline
\end{tabular}

effects than the absence of a single residue, as observed for the most common $\Delta$ F508 mutation. However, considerable evidence has already been published to support the hypothesis that in the absence of a functional allele, the total absence of the

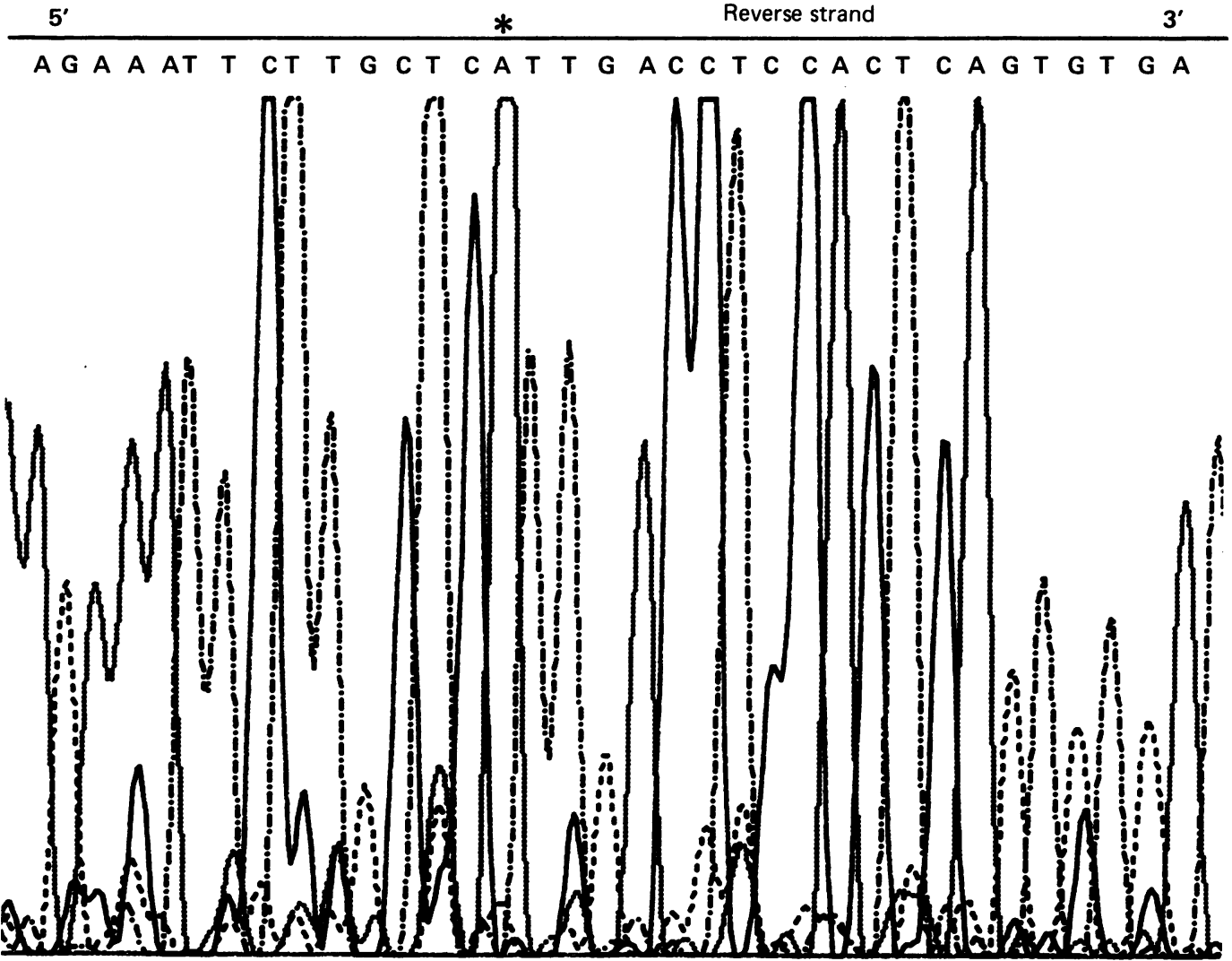

Sequence analysis of the patient's exon 11. DNA was amplified with primers 11 i-5' and 11 i- $3^{\prime 3}$ in $40 \mathrm{cycles}\left(1 \mathrm{~min} 92^{\circ} \mathrm{C}\right.$, $\left.45 \mathrm{~s} 35^{\circ} \mathrm{C}, 2 \mathrm{~min} 63^{\circ} \mathrm{C}\right) .1 \mu \mathrm{l}$ of this reaction was subjected to $25 \mathrm{cycles}$ of asymmetrical $\mathrm{PCR}\left(30 \mathrm{~s} 94^{\circ} \mathrm{C}, 1 \mathrm{~min} 50^{\circ} \mathrm{C}\right.$, 2 min +5 s extension per cycle $72^{\circ} \mathrm{C}$ ) with 50 pmol primer $11 i-5^{\prime}$ and 1.5 pmol primer $C F 11 R M$

(5'-TGTAAAACGACGGCCAGTAAATGCTTGCTAGACC), the latter containing an M13 primer binding site for single strand sequencing. Sequence analysis of the asymmetrical PCR product displays the reverse strand. The homozygous C1789GA to TGA substitution, indicated by the asterisk, results in a UGA stop codon. 
CFTR protein is more likely to be compatible with certain cell or tissue requirements than the presence of an altered CFTR product in the cell membrane. A better understanding of this phenomenon might be obtained by studying the pattern of expression in the various tissues, especially in those rare patients who are homozygous for the described mutations. So far, no cell lines are available from our patient, but epithelial cells are currently being studied at the mRNA level.

The authors thank the patient and his family for cooperation, Drs Domagk (Göttingen) and Döhmen (Aachen) for providing clinical data, Bettina Pape for technical help, and David N Cooper for reading the manuscript. This study was supported by grants from the Deutsche Forschungsgemeinschaft and the Bundesministerium für Forschung und Technologie.
1 Rommens JM, Iannuzzi MC, Kerem BS, et al. Identification of the cystic fibrosis gene: chromosome walking and jumping. Science 1989;245:1059-65.

2 Riordan JR, Rommens JM, Kerem BS, et al. Identification of the cystic fibrosis gene: cloning and characterisation of complementary DNA. Science 1989;245:1066-73.

3 Cutting GR, Kasch LM, Rosenstein BJ, et al. A cluster of cystic fibrosis mutations in the first nucleotide-binding fold of the cystic fibrosis conductance regulator protein. Nature 1990;346:366-9.

4 Kerem BS, Zielenski J, Markiewicz D, et al. Identification of mutations in regions corresponding to the two putative nucleotide (ATP)-binding folds of the cystic fibrosis gene. Proc Natl Acad Sci USA 1990;87:8447-51.

5 Kerem BS, Rommens JM, Buchanan JA, et al. Identification of the cystic fibrosis gene: genetic analysis. Science 1989; 245:1073-80.

6 Cuppens H, Marynen P, De Boeck C, et al. A child, homozygous for a stop codon in exon 11, shows milder cystic fibrosis symptoms than her heterozygous nephew. $\mathcal{f}$ Med Genet 1990;27:717-19.

7 Cutting GR, Kasch LM, Rosenstein BJ, et al. Two patients with cystic fibrosis, nonsense mutations in each cystic fibrosis gene, and mild pulmonary disease. N Engl $\mathcal{F}$ Med 1990;323:1685-9.

8 European Working Group on CF Genetics. Gradient of distribution in Europe of the major CF mutation and of its associated haplotype. Hum Genet 1990;85:436-45. 